\title{
Endoscopic resection as a primary palliative therapy for advanced primary malignant melanoma of the esophagus
}

\author{
Manne Manasa, Palakurthi Muralikrishna, L. R. S. Girinadh \\ Department of Gastroenterology, King George Hospital, Visakhapatnam, Andhra Pradesh, India
}

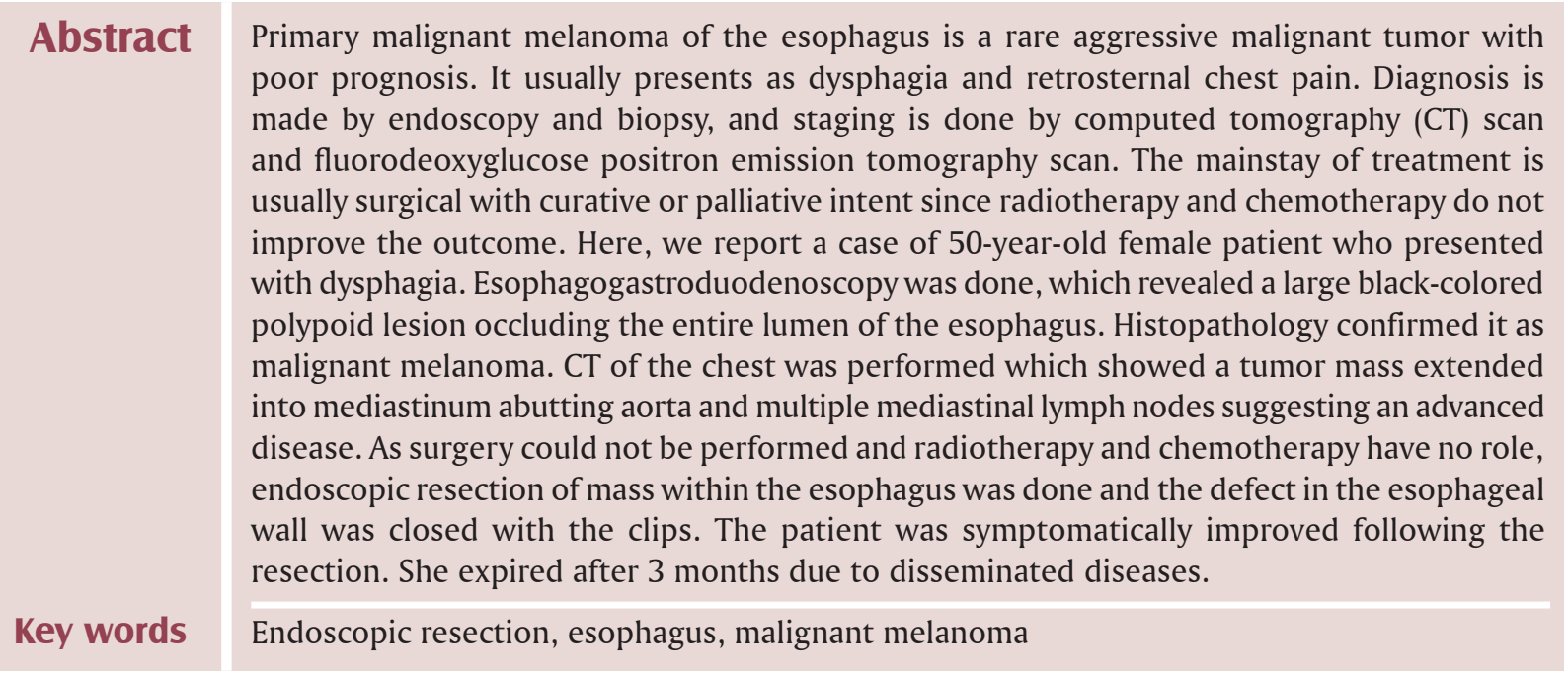

\section{Introduction}

Primary malignant melanoma of the esophagus (PMME) is a malignant tumor which occurs in the melanin cells of esophageal mucosal epithelial basal layer. PMME is a rare neoplasm that accounts for $0.1 \%-0.2 \%$ of all primary neoplasms of the esophagus and $0.5 \%$ of visceral melanomas. $^{[1]}$

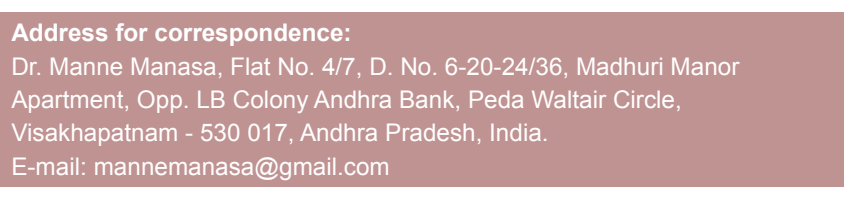

\begin{tabular}{|l|c|}
\hline \multicolumn{2}{|c|}{ Access this article online } \\
\hline \multirow{2}{*}{$\begin{array}{l}\text { Website: } \\
\text { www.jdeonline.in }\end{array}$} & Quick Response Code \\
\hline DOI: & \\
$10.4103 / 0976-5042.202819$ & \\
&
\end{tabular}

Although PMME was first reported in $1906^{[2]}$ and confirmed with histological evidence in $1952{ }^{[3]}$ the diagnosis remained controversial until 1963 when the presence of benign melanocytes within the esophageal mucosa was demonstrated. ${ }^{[4]}$ This observation was confirmed later in two other studies. ${ }^{[5]}$

Risk factors are not yet defined, but esophageal melanosis has been indicated as predisposing factor. ${ }^{[6]}$ The PMME most often affects patients between the sixth and seventh decade of life. There is a 2.02:1 male predominance. Most patients are symptomatic on presentation, and dysphagia is the most common symptom, followed by weight loss, substernal, or

This is an open access article distributed under the terms of the Creative Commons Attribution-NonCommercial-ShareAlike 3.0 License, which allows others to remix, tweak, and build upon the work non-commercially, as long as the author is credited and the new creations are licensed under the identical terms.

For reprints contact: reprints@medknow.com

How to cite this article: Manasa M, Muralikrishna P, Girinadh L. Endoscopic resection as a primary palliative therapy for advanced primary malignant melanoma of the esophagus. J Dig Endosc 2017;8:29-32. 
epigastric discomfort. The duration of symptoms before presentation is short approximately 3 months in most cases. ${ }^{[7]}$

A polypoidal, pigmented lesion in the lower two-thirds of the esophagus is the typical endoscopic finding. ${ }^{[8]}$ Less frequently, they are nonpigmented, but melanin can be identified in histological examination in a large proportion of those cases, and the true incidence of amelanotic melanoma of the esophagus is $<2 \%$. ${ }^{[9]}$

Thoracic and abdominal computed tomography (CT), fluorodeoxyglucose positron emission tomography-CT, and endoscopic ultrasonography are useful as staging methods. ${ }^{[10]}$

Most PMME are diagnosed at advanced stage of the disease. ${ }^{[8]}$ Although there is no formal recommendation, surgery is the preferential method of treatment, but the prognosis remains poor.

\section{Case Report}

A 50-year-old female patient presented with progressive dysphagia for 2 months with dysphagia score of 3 at the time of presentation. She had one episode of hematemesis associated with malena and retrosternal chest discomfort and constitutional symptoms. Her Glasgow-Blatchford score was 11 at presentation. The patient was hemodynamically stabilized and was subjected to endoscopy. Esophagogastroduodenoscopy was performed with Optera Video Gastrointestinal Scope GIF-H17 and found to have a large pigmented polypoidal mass at $28 \mathrm{~cm}$ from incisors occluding the entire lumen [Figure 1]. It was reported as spontaneous esophageal hematoma or aortoenteric fistula with large hematoma or ulcerated mass with blood clot. CT of the chest with oral contrast was performed, and it revealed a large mass with heterogeneous echogenicity in the esophagus extending into the mediastinum closely abutting the aorta [Figure 2]. Multiple lymph nodes were noted in the mediastinum with a small metastatic deposit in the liver [Figure 3]. After excluding the possibility of hematoma, repeat endoscopy was done. Endoscope was passed gently and found that the mass extended from 28 to $35 \mathrm{~cm}$ from incisors. Beyond the mass, few satellite lesions with smooth black surface were noted [Figure 4] giving a clinical impression of malignant melanoma. Biopsy was taken from the mass and satellite lesions and sent for histopathological examination. Microscopic examination revealed multiple tumor cells with intra- and extracellular pigmentation consistent with malignant melanoma [Figure 5]. One section showed that tumor cells arise from junctional complex [Figure 6] which suggests that the tumor arises from esophagus. Immunohistochemical staining confirmed it as malignant melanoma. Workup for primary site of origin did not reveal any other primary focus. As the tumor is in advanced stage with mediastinal involvement, surgery cannot be performed. Malignant melanoma is not responsive to chemotherapy or radiotherapy. Her Eastern Cooperative Oncology Group performance status was 2.
To improve her dysphagia, endotherapy was planned as a palliative treatment. Endoscopic resection of polypoidal lesion

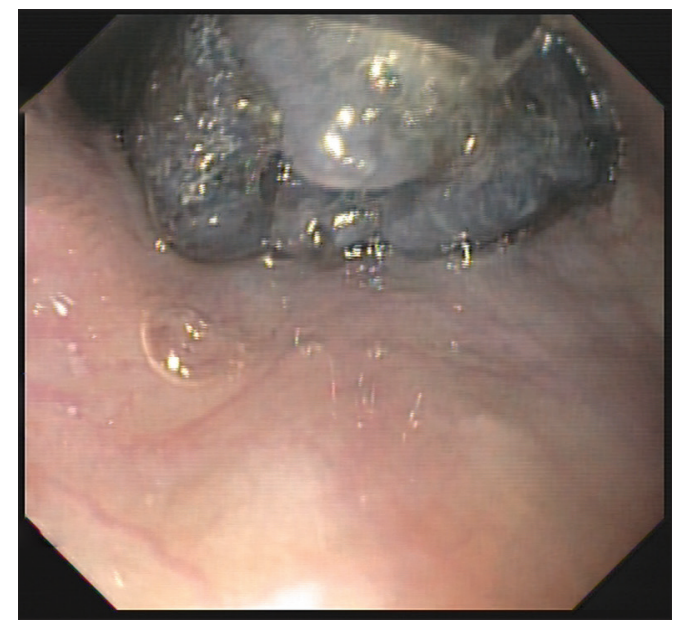

Figure 1: Endoscopy showing large pigmented polypoidal lesion

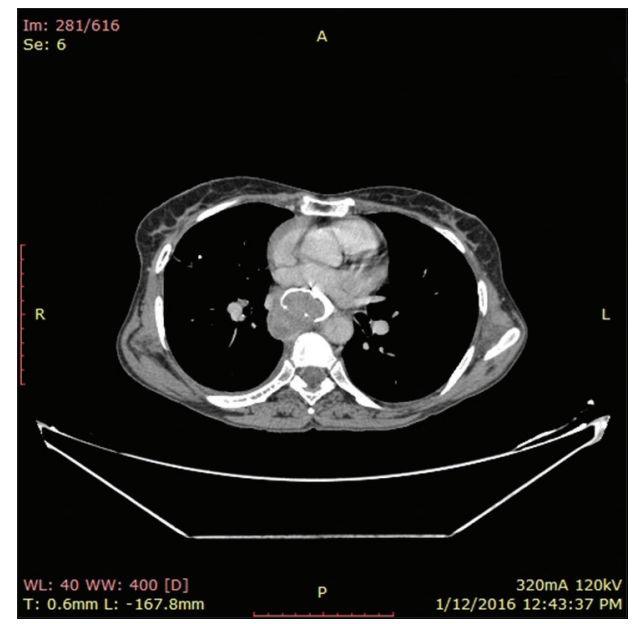

Figure 2: Contrast-enhanced computed tomography showing large heterogeneous mass in the esophagus extending into mediastinum abutting aorta

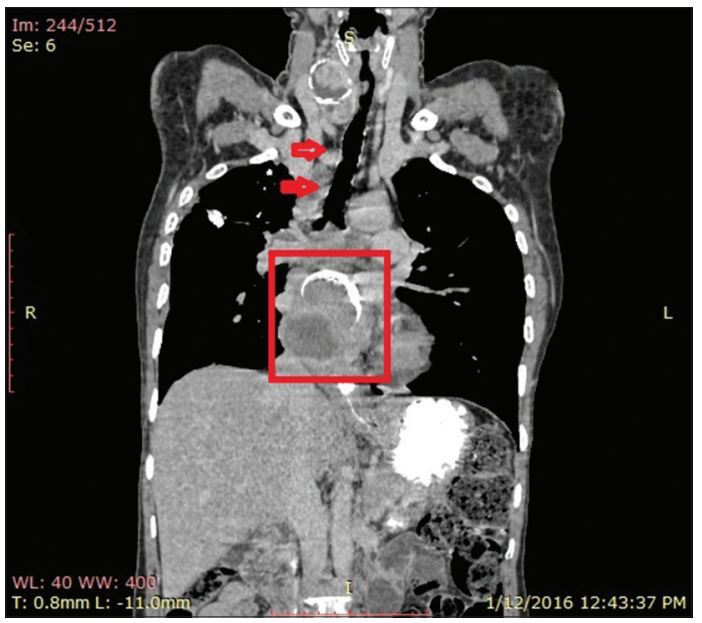

Figure 3: Contrast-enhanced computed tomography showing mass in the esophagus and multiple mediastinal lymph nodes 
was done in piecemeal using snare. Oozing of blood from the tumor bed was controlled with argon plasma coagulation. The defect in the esophageal wall was closed using the cook instinct endoscopic hemoclips [Figure 7]. After endoscopic resection, the dysphagia score improved to 1 . The patient expired after 3 months due to disseminated disease.

\section{Discussion}

We presented a rare case report of PMME and for the first time reported endoscopic palliative resection of the tumor mass.

By the year 2011, only 337 cases had been reported worldwide, most of which being single case reports and most of the cases being males. ${ }^{[11]}$ Here, we report a female patient with malignant melanoma of esophagus.

The majority of PMME patients presents with the complaints of dysphagia, nonspecific retrosternal pain, and weight loss. This patient presented with dysphagia and upper gastrointestinal tract bleeding which is an unusual presentation.

The PMME diagnostic criteria defined in the study by Allen and Spitz ${ }^{[12]}$ include: (i) a typical histological pattern of melanoma and the presence of melanin granules within the

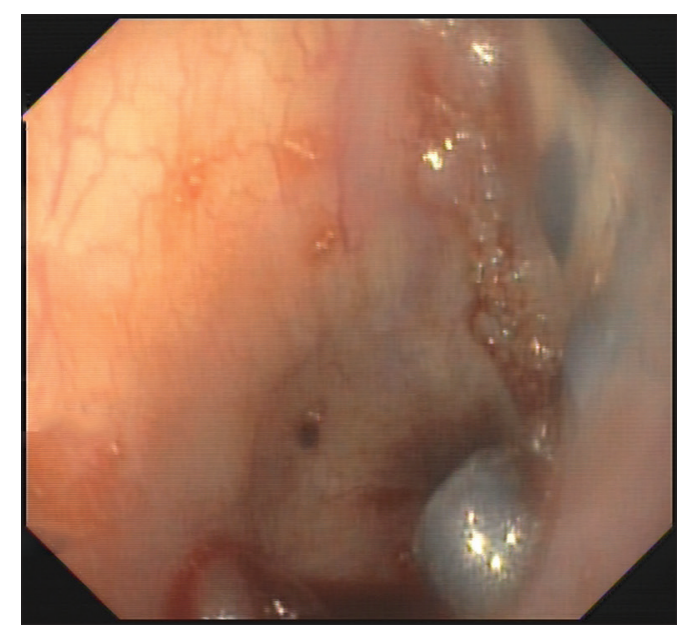

Figure 4: Repeat endoscopy showing satellite lesions beyond the mass

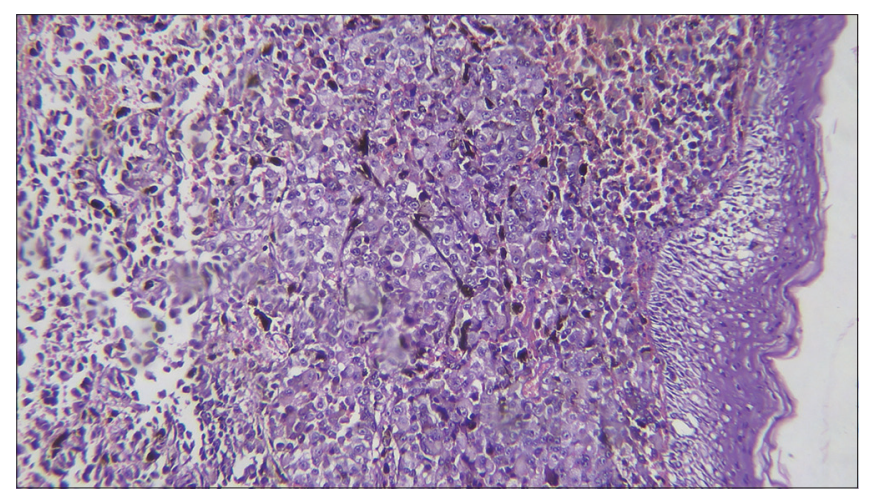

Figure 6: HPE showing junctional activity tumor cells; (ii) an origin in an area of junctional change within the squamous epithelium; and (iii) junctional activity with melanotic cells in the adjacent epithelium. These criteria, along with the presence of in situ melanoma and/or satellite tumors with no previous history of cutaneous melanoma, and a systematic investigation with pathological examination are required for a definitive diagnosis of PMME. All these criteria were fulfilled in the present case.

No gold standard has been established for the treatment of PMME. Kimura et al.${ }^{[13]}$ reported the use of endoscopic mucosal resection for the treatment of early PMME and recorded no recurrence after 18 months. Consistent with this finding, Cheung et al ${ }^{[14]}$ evaluated the surveillance, epidemiology, and end results database of primary gastrointestinal melanomas (1973-2004) and identified complete surgical resection as the only identifiable treatment strategy that significantly improved survival in PMME patients. The present patient has extensive disease which is not possible for resection.

Alternative nonsurgical or surgical adjuvant therapies for PMME patients include chemotherapy, chemoradiotherapy, endocrine therapy, and immunotherapy; however, these treatment strategies have not shown any benefit, and they are

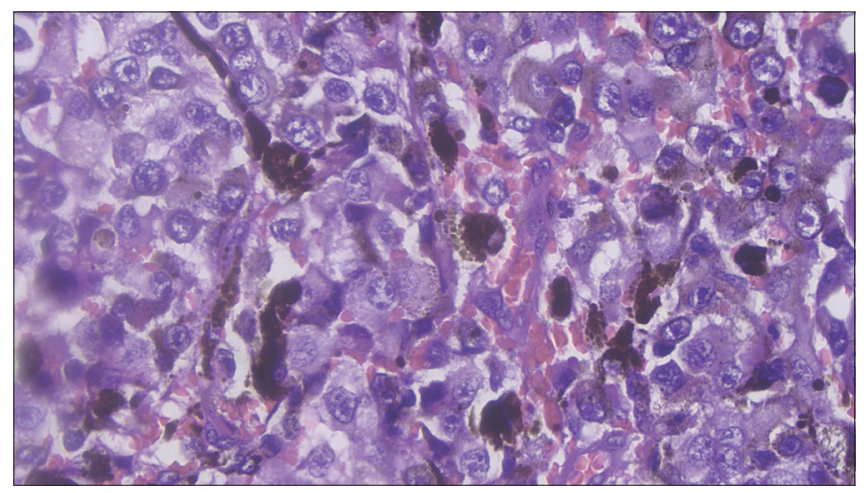

Figure 5: Histopathological Examination (HPE) showing large tumor cells with intracellular and extracellular melanin deposition

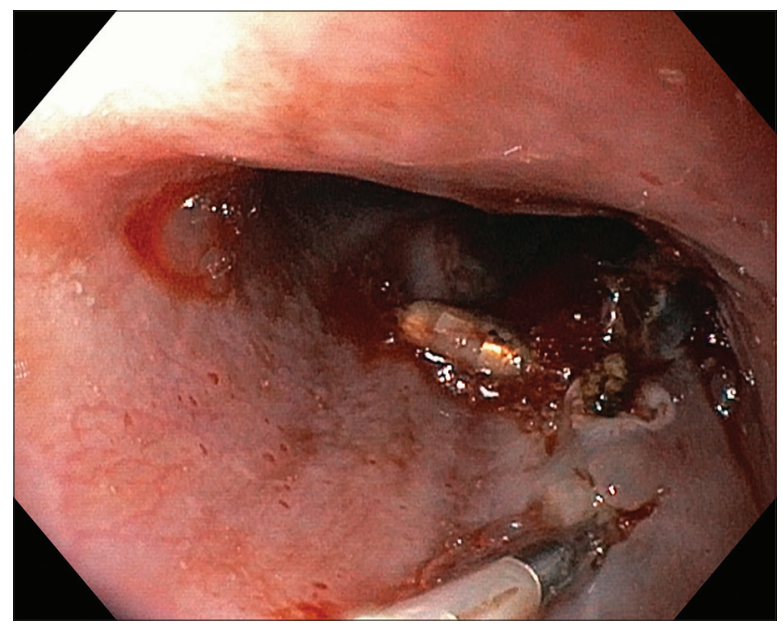

Figure 7: After endoscopic resection, hemoclips were placed 
not fully evaluated. Hence, chemoradiotherapy was not given to this patient.

As her performance status was good, we did endoscopic resection to improve her dysphagia as a palliative therapy. After endoscopic resection, her dysphagia scores improved to 1 and went home. She expired after 3 months due to disseminated disease.

\section{Financial support and sponsorship}

Nil.

\section{Conflicts of interest}

There are no conflicts of interest.

\section{References}

1. Volpin E, Sauvanet A, Couvelard A, Belghiti J. Primary malignant melanoma of the esophagus: A case report and review of the literature. Dis Esophagus 2002;15:244-9.

2. Baur EH. A case of primary melanoma of the esophagus. Arb Geb Pathol Anat Inst Tubingen 1906;5:343-54.

3. Garfinkle JM, Cahan WG. Primary melanocarcinoma of the esophagus; fist histologically proved case. Cancer 1952;5:921-6.

4. De la Pava S, Nigogosyan G, Pickren JW, Cabrera A. Melanosis of the esophagus. Cancer 1963;16:48-50.

5. Tateishi R, Taniguchi H, Wada A, Horai T, Taniguchi K. Argyrophil cells and melanocytes in esophageal mucosa. Arch Pathol 1974;98:87-9.

6. Ohashi K, Kato Y, Kanno J, Kasuga T. Melanocytes and melanosis of the oesophagus in Japanese subjects - Analysis of factors effecting their increase. Virchows Arch A Pathol Anat Histopathol 1990;417:137-43.

7. Zheng J, Mo H, Ma S, Wang Z. Clinicopathological findings of primary esophageal malignant melanoma: Report of six cases and review of literature. Int J Clin Exp Pathol 2014;7:7230-5.

8. Chalkiadakis G, Wihlm JM, Morand G, Weill-Bousson M, Witz JP. Primary malignant melanoma of the esophagus. Ann Thorac Surg 1985;39:472-5.

9. Watanabe H, Yoshikawa N, Suzuki R, Hirai Y, Yoshie M, Ohshima H, et al. Malignant amelanotic melanoma of the esophagus. Gastroenterol Jpn 1991;26:209-12.

10. Li YH, Li X, Zou XP. Primary malignant melanoma of the esophagus: A case report. World J Gastroenterol 2014;20:2731-4.

11. Bisceglia M, Perri F, Tucci A, Tardio M, Panniello G, Vita G, et al. Primary malignant melanoma of the esophagus: A clinicopathologic study of a case with comprehensive literature review. Adv Anat Pathol 2011;18:235-52.

12. Allen AC, Spitz S. Malignant melanoma; a clinicopathological analysis of the criteria for diagnosis and prognosis. Cancer 1953;6:1-45.

13. Kimura H, Kato H, Sohda M, Nakajima M, Fukai Y, Miyazaki T, et al. Flat-type primary malignant melanoma of the esophagus treated by EMR: Case report. Gastrointest Endosc 2005;61:787-9.

14. Cheung MC, Perez EA, Molina MA, Jin X, Gutierrez JC, Franceschi D, et al. Defining the role of surgery for primary gastrointestinal tract melanoma. J Gastrointest Surg 2008;12:731-8. 